\title{
No More Bystanders- Grandchildren of Hiroshima and the 70th Anniversary of the Atomic Bomb
}

DOI:

10.1162/DRAM_a_00649

\section{Document Version}

Final published version

Link to publication record in Manchester Research Explorer

\section{Citation for published version (APA):}

Thompson, J. (2017). No More Bystanders- Grandchildren of Hiroshima and the 70th Anniversary of the Atomic Bomb. TDR - The Drama Review - A Journal of Performance Studies, 61:2(T234), 87-104.

https://doi.org/10.1162/DRAM_a_00649

\section{Published in:}

TDR - The Drama Review - A Journal of Performance Studies

\section{Citing this paper}

Please note that where the full-text provided on Manchester Research Explorer is the Author Accepted Manuscript or Proof version this may differ from the final Published version. If citing, it is advised that you check and use the publisher's definitive version.

\section{General rights}

Copyright and moral rights for the publications made accessible in the Research Explorer are retained by the authors and/or other copyright owners and it is a condition of accessing publications that users recognise and abide by the legal requirements associated with these rights.

\section{Takedown policy}

If you believe that this document breaches copyright please refer to the University of Manchester's Takedown Procedures [http://man.ac.uk/04Y6Bo] or contact uml.scholarlycommunications@manchester.ac.uk providing relevant details, so we can investigate your claim.

\section{OPEN ACCESS}




\section{No More Bystanders}

\section{Grandchildren of Hiroshima and the 70th Anniversary of the Atomic Bomb}

\section{James Thompson}

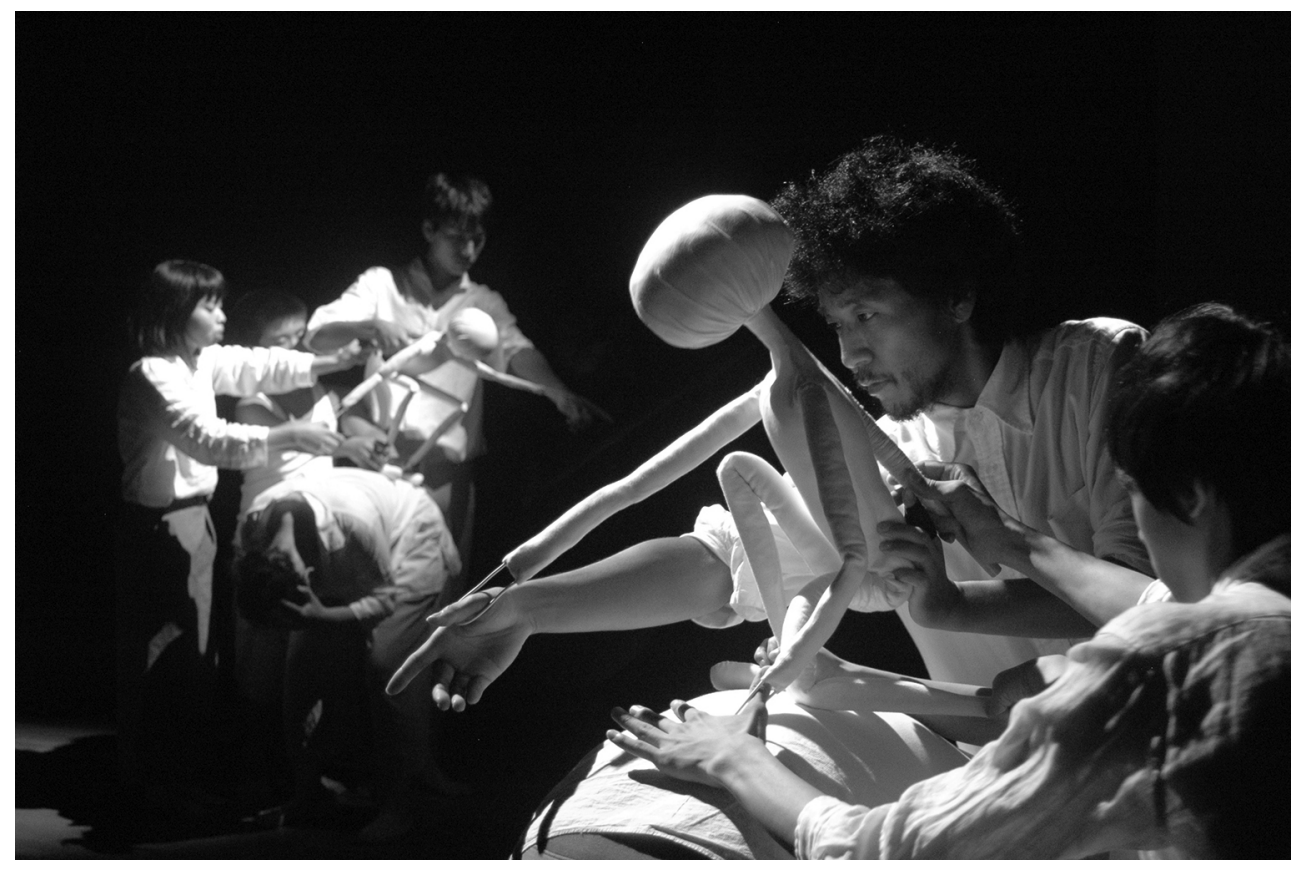

\section{Preface-The Lift}

To articulate the past historically does not mean to recognize it "the way it really was" [...] It means to seize hold of a memory as it flashes up at a moment of danger.

Itchy Knees. Sun Sea. Go!

In April 2015, I was taking part in the devising stage of London Bubble Theatre's Grandchildren of Hiroshima project in a high-rise cultural center in downtown Hiroshima. At the end of one of the early workshops, I entered the lift to leave and one young participant got in after me. She was about 10 years old. We were on the sixth floor going down to the ground.

She smiled and counted the buttons. Ichi, ni, san, shi, go.

One, two, three, four, five. I repeated with ease.

She laughed and pointed to six, seven, and eight. Roku, nana, hachi. 
No idea - I could not speak the words that she had said.

Taught to me by my father, I have known one to five in Japanese my whole life. Until that moment I had never heard the Japanese words for six, seven, or eight. I cannot remember not knowing the first five. Icbi ni. San shi. How could a small boy not like the idea of "itchy knees" and "sun" and "sea"? And the delight of counting from one to four and then shouting - "GO!"

Roku, nana, hacbi. Hacbi Roku. Eight six - 8/6. August 6th - as tumultuous a memorial date for the Japanese 20th century as 9/11 will be for an American 21st. Numbers I could not say.

But here in a lift with a young girl in Hiroshima in 2015, they flashed in front of me, and the article that follows is an exercise in seizing hold of the memories that flowed from this moment.

\section{The Impossible Bystander}

What does occur is that each reader of atomic-bomb literature is drawn into a moral quagmire: if the sum total of the story is not simply an elaboration of exchange between victim and victimizer, there is suddenly and uncomfortably new room provided for the reader too. Where, after all, is the bystander [...] in the ethical implications of Hiroshima and Nagasaki? (Treat 1995:368)

HIBIKI: Meeting Menda San made everything much more real. I felt I could ask personal questions - ones that I really wanted to find out the answers to. (in Setoyama 2015:27)

On 6 August 2015 Japan marked the 70th anniversary of the USA's atomic attack against the city of Hiroshima, which by the end of 1945 was responsible for the deaths of over 140,000 residents of that city. The bombing of Hiroshima was followed by the attack on Nagasaki three days later, and 70 years on in 2015 both cities commemorated their respective destruction with augmented versions of the ceremonies that they have conducted since those events in 1945.

Grandchildren of Hiroshima was designed specifically for the 70th anniversary, and while it is not beyond the critique faced by other Japanese memorial practices (see for example Saito [2006], Miyamoto [2012], or Zwigenberg [2014]), I argue that it was respectfully embedded in the context of existing programs and also in conversation with them. The play, as well as its preparation, had particular connection with the present-day Japanese politics of memory, but also engaged in what Yuki Miyamoto has called a "dialogue with the dead" (2012:77). The surprise in identifying those dead — my "memory flash" in the lift — was what drew me into a very direct attempt to answer John Whittier Treat's question about the location of the bystander in the "ethical implications of Hiroshima and Nagasaki." My initial focus on Grandchildren of Hiroshima, therefore - a play that I suggest exhibited, following Lisa Yoneyama, a "tactful strategy of critical remembering" (Yoneyama 1999:217) — took on a broader scope as it succeeded in placing this particular "bystander" into relation with his own memories of nuclear war.

Figure 1. (previous page) Actors including Rio Maniwa, Kantaro Matsuo, Nori Ikdea, and Jun Matsu bring the puppets to life, evoking the huge number of accounts of the deaths of children in the bombing. Grandchildren of Hiroshima, August 2015, Aster Plaza, International Youth House, Hiroshima. (Photo by London Bubble Theatre)

James Thompson is Professor of Applied and Social Theatre and Associate Vice President for Social Responsibility at the University of Manchester. He is the Founder and Co-Director of In Place of War-a project researching and developing arts programs in war and disaster zones (inplaceofwar.net). He has developed and run theatre projects in Africa and South Asia (principally DR Congo and Sri Lanka). His most recent books are Performance Affects: Applied Theatre and the End of Effect (Palgrave Macmillan, 2009) and Humanitarian Performance: From Disaster Tragedies to Spectacles of War (Seagull Books, 2014). james.thompson@manchester.ac.uk 
In his book The Contract of Mutual Indifference (1998), Norman Geras constructs a "political philosophy after the Holocaust" based on the failure of the bystander to act when witnessing the disappearances and murders of his or her neighbors. According to his account, preventing future genocides will require a radical realignment of our responsibility to the other, and in particular we will have to tear up the contract of mutual indifference and replace it with one of ethical regard. This analysis echoes a broader 20th-century philosophical preoccupation with the notion of the witness. If we, as artists, writers, and activists, are concerned with the role of the witness when faced with the numerous incidents of horror and suffering in the 20th and early 21 st centuries, our attention owes much to the catastrophic failure to demand a culture of mutual care at the time of the Holocaust. However, the US atomic attacks on Hiroshima and Nagasaki in August 1945 raise a qualitatively different challenge - if we allow them to do so.

As mass atrocities committed by the United States, and supported by her European allies, the atomic bombing of two Japanese cities challenges the standard perpetrator, victim, and witness triangle that structures many Western critical approaches to war or suffering. Significantly for what follows, Hiroshima and Nagasaki were not acts of mass violence that made distinctions between witness and victim - no one watched as the citizens of Hiroshima and Nagasaki were taken away to their deaths. If Geras's analysis asks why the German citizen did not do more to protect his or her Jewish neighbors, an analysis of Hiroshima must recognize that the bomb killed all citizens, no matter their religion, age, or affiliation. There were no non-Japanese witnesses as such and we must therefore ask, with Treat, in his extensive study of post-bomb Japanese literature: "Where, after all, is the bystander?" All people in Japan were intended or potential targets of the atomic bombs; people beyond Japan, citizens of the US, and all other parts of the world, were its intended beneficiaries. We are not witnesses, audiences, bystanders - the bomb addressed us all as participants in its performance.

Asking "where, after all, is the bystander" is central to my perspective on the Grandchildren of Hiroshima theatre project - developing, rehearsing, and performing a play during the period marking the 70th anniversary of the bombing of Hiroshima in August 2015. By suggesting that the notion of "bystander" holds little sway theoretically in critically appraising a response to the bombing of Hiroshima, I am asking: what does it mean to perform a play that by its very nature requires an audience? Who were we, watching the performances, if not witnesses? What were we doing if we were not the bystanders being petitioned, in Geras's sense, to shed our mutual indifference and accept a contract of mutual regard and responsibility to the stories of the bombing presented before us? As has been argued by Yoneyama, if "the memories and testimonies of Hiroshima, and the state of the postcolonial, postnuclear age that they speak to, forbid virtually anyone from remaining external to this global condition" and if subsequently, "there is no space for the traditional ethnographer who can presume to be transcendent and impartial" (1999:39), what is my role as the critic when watching this particular play?

My argument is that there are no bystanders, no transcendent ethnographers, in atomic critique - there are only people addressed as participants who have a relationship to the material that needs to be realized and acknowledged. We were not being petitioned to act, but being brought into relation, and perhaps back into relation, with a history to which we are already intimately connected.

And for me, personally, as someone taught to count to five in Japanese sometime before I can remember by a father who, as a British soldier during WWII, was held in captivity by the Japanese for three years in POW camps on the Burma-Thailand railway and whose life story was articulated as survival thanks to Hiroshima, accepting my role as participant is the position from which this article must be written. I am no bystander - and the challenge here is that this must be the same for anyone observing this piece of anniversary performance. And this realization seized me with particular urgency in a tiny moment in a lift with a young Japanese actor. In watching the workshops, rehearsals, and performance of Grandchildren of Hiroshima, and now writing about them, I freely acknowledge that there is no space for the traditional ethnographer and 
accept how my experience of this play led to a series of memories that flashed perhaps not dangerously in Benjamin's sense, but certainly as moments that produced in me a deeply troubled, embodied response.

\section{Grandchildren of Hiroshima}

Residues of Hiroshima's catastrophe are constantly in danger of being recuperated for the establishment of coherent national narratives and identities. Nevertheless, these shards of memory, as traces, also carry the power to obstruct that same process. Countering and deferring the relentless processes through which nationalizing and renationalizing take place, tactful strategies of critical remembering, of piecing together the fragmented past, will take skill. (Yoneyama 1999:217)

Grandchildren of Hiroshima is a London Bubble Theatre project in partnership with Japanese artists who developed the 70th anniversary performance from a series of children's interviews with elders who survived the atomic bomb. Initiated by the London-based company after a similar project exploring the impact of the Blitz, Japanese artists and company members conducted the first meetings, workshops, and interviews in 2014. During 2015 the company made extended visits, principally to Hiroshima, in April and then July through August 2015. As the play's narrator, performed by different actors throughout the show, explains straightforwardly, "these are the interviews of the children of Hiroshima back then, done by the children of Hiroshima today" (Setoyama 2015:4). While the children were of varying ages, the project was premised on the creative potential of 10-year-olds interviewing people who were 10 in 1945. They did not always ask the "correct" questions - did the Americans really give you chocolate, did you really eat insects - and this was the point. The unusual perspective of contemporary children perhaps helped provide a different angle on the extraordinary experience of those historical children. The play showed these struggles for cross-generational understanding. One of the survivors repeatedly says in the script, "I wonder if you understand what I mean" (Setoyama 2015:6), suggesting that this urge to communicate was as much a topic for the play as the content of the stories.

It was a project that Yuki Miyamoto might refer to as "beyond the mushroom cloud" (2012) in the sense that rather than a view from above taking in the iconic perspective over the city of Hiroshima, it was made up of the lives and struggles of those living within and beneath that cloud in the immediate period after the bombing. The transcribed interviews became the source material for the workshops and eventual play script written by Misaki Setoyama. I joined the rehearsal workshops run by Jonathan Petheridge (artistic director of London Bubble) and Yorie Akiba in April 2015 and also the final week of rehearsal leading to the performances, produced by Marigold Hughes and Yukie Ogansawar, during the week of commemorative events around 6 August that same year.

Hibakusha - survivors of the atomic bomb - have been central to the politics of remembrance of the nuclear attacks since the immediate postwar period. They have been active participants in what Akiko Hashimoto has called the "battle over war history" that has been part of a "long, explosive culture war in Japan for decades, vying for the hearts and minds of the next generation" (2015:89) — even if actually very few of the many thousands of survivors, according to Lisa Yoneyama, "have openly voiced their survival memories" (1999:89). The Grandchildren of Hiroshima project was, therefore, part of that "culture war" continuing a struggle for versions of the past and staking a claim to the significance of that past in contemporary Japan. Interviewing the hibakusha elders for the play was also part of a tradition that had in particular emerged since the 1980s when they increasingly took roles as storytellers (Yoneyama 1999:35), but it had added pathos at the time of the 70th anniversary because the number of living hibakusha was, inevitably, growing smaller. As Miyamoto explains, "the fact that the number of hibakushas decreases each passing year makes more urgent the question of the responsibility of nonhibakushas in learning from hibakushas' experience" (2012:147). 
Grandchildren of Hiroshima was, therefore, one example of the exercise of that responsibility, through which young non-hibakusha were seeking to learn from hibakusha, in this case through the creation of a piece of performance. While the project was based on London Bubble's longstanding commitment to intergenerational theatre - $\mathrm{a}$ form where young people perform alongside elders on themes of mutual concern - the company made no claim that this piece would be unique or unusual for Japan. Having completed a piece called Grandchildren of the Blitz in 2011, commemorating the bombing of London in WWII, a London Bubble artist who had a long-term connection to Japan negotiated the new project with artists and playwrights she knew there. The project grew collaboratively from early discussions with Japanese and London Bubble artists and was understood very much as part of cultural practices within the country, where a "growing number of cultural institutions [...] play a pivotal role in producing generational memory as the wartime generation passes on and stories of direct war experience become less available at home" (Hashimoto 2015:85).

The first stage of the project was to train the young people to interview the hibakusha elders. These interviews were then transcribed and the subsequent texts were worked into a play script - a process that was done through practical exploration in a series of workshops with the future cast and also by the playwright Misaki Setoyama. The final piece concentrated on the stories of 11 interviewees - presenting vignettes of their lives before the bombing, in the immediate aftermath, and for a short period after the end of the war.

For example, Akito Kono explained how he had resisted conscription through feigning poor eyesight; Hiroe Sata recalled showing off the dried bananas and grape sugar her family was fortunate to have access to; and Yoshiko Kajimoto talked of her struggle looking after her boisterous brothers after the bombing. Life in the immediate aftermath of the A-bomb was shown in different short scenes of searching for dead friends or relatives, or the terror of fleeing the city. The final sections of the play comprised recollections of the gradual rebuilding of the city and the tentative engagement with the American soldiers, Japan's new occupiers. The play ended with a number of statements from the children who emerged from their role as interviewers of the elders with their own questions about how a peaceful world free from violence might be built. For example, one young boy suggested: “I don't think Japan needs soldiers — just a selfdefense army for helping and rescuing” (Setoyama 2015:27).

A key concern about A-bomb art that has been the focus of practice and commentary is echoed - and in fact restaged - within the piece. This shared concern centers on the acknowledged oscillation between the work as documentary account and as creative response. This tension has been identified by Treat as dialectical, so that many authors and poets have sought to manage "the larger confrontation between the rigors of historical writing and the play of imagination" (1995:33). Grandchildren of Hiroshima, therefore, in presenting a script that directly quotes the words of the hibakusha and presents recorded voice-overs of their interviews, situated itself directly within this dynamic. This, of course, also places the work in a wider international movement of what Carol Martin has called "theatre of the real" (2012), and what Marvin Carlson has identified as the vital intersection between performance and memory (2003). Here, the testimonial practice on which the research for the piece had been based was revealed as a central device throughout the play, and as the participant/character Hibiki attests in performance these encounters had "made everything much more real" (Setoyama 2015:27). The play did not seek to conceal its devising process, rather it laid the methods that were at the heart of its construction at the center of both the text and its staging.

Young children played themselves as interviewers of the elders onstage and the transition from interview to stylized scene was conspicuous. Yoneyama notes how hibakusha narratives "always display two contradictory impulses, to factualize and to allegorize" (1999:212) and these impulses remained visible in Grandchildren of Hiroshima. The tension between Hiroshima as history, where accounts of the bombing insist on its particular facticity, and Hiroshima as broader allegory, where creative response enables the story of the bombing to claim a more general 
significance, is seen repeatedly in Japanese postwar nuclear literature and criticism. In showing the construction of the narratives of the hibakusha and then the transformation of these texts into scenes of domestic life, Grandchildren of Hirosbima seemed to place this tension at the heart of its research, devising, and presentational approach.

\section{August 2015}

After the workshop devising period in April 2015, the final rehearsals began in July and early August and then four performances took place starting on 6 August, the day of the 70th anniversary, and ending on the 8th, to an audience of between 50 and 100 Japanese and international visitors each time. Early on the morning of 6 August there was a major ceremony timed to coincide with the exact moment that Enola Gay, the US B-29 Superfortress bomber, dropped her "Little Boy" atomic bomb. Dignitaries from all over the world, peace delegations from Japan and beyond, and thousands of citizens sat under hot awnings to hear speeches from Prime Minister Sinzo Abe and the current mayor of Hiroshima, Kazumi Matsui, for wreaths to be laid, and for the peace hymn to be sung. Grandchildren of Hiroshima was one of numerous events held on that day, from concerts and art exhibitions to more intimate opportunities for visitors to meet and hear directly from survivors of the bombing. The two major galleries in the town - Hiroshima City Museum of Contemporary Art (MOCA), and the Prefectural Art Museum (PAM) - both had exhibitions relating directly to the bombing that offered clear examples of the key tropes of atomic bomb imagery that the play shared and reflexively recirculated.

While there is no singular way of representing the results of the devastating destruction of the two cities, alongside the debate between the documentary and the imaginary (that at times exists within the same piece of work, such as Masuji Ibuse's novel, Black Rain [2012]) there are images that continue to circulate in A-bomb works. This is part of what Hashimoto has referred to as a "conflictive and polyphonic public discourse" where instead of a "monolithic, consensual picture" different objects, images, and representations of the bombing and its aftermath either reinforce, complement, or counter each other" (2015:14). These circulating images operate in the intersecting space between documentary and literary representations as suggested above, and in commemorative spaces, curated exhibitions, and the visual arts of survivors, and in the work of both established and professional artists. The range of responses has been expertly documented in the work of Treat (1999) and Robert Jacobs (2010) but for the purpose of this argument, it is important to note how one of the most striking tropes is linked to the ability of the bomb itself to make images. A frequently discussed and repeatedly represented aspect of the August morning bombing of the city is connected to the way that the heat from the initial explosion vaporized people, leaving permanent shadow-like imprints on their surroundings.

One such seared image is seen in the Hiroshima Peace Memorial Museum, which displays the actual edge of a wall from the Sumitomo Bank, with the shape of a person in dark outline - someone who was sitting on a curb when the bomb exploded. This image has become a frequent point of reference for those seeking to represent the bomb, or a point of comment for those writing about it. John Dower, for example, writes of the "permanent white shadows on scorched walls where what had made the shadow (grass, ladders, people) no longer existed" (2012:153); and Miyamoto notes "the searing flash from the explosion that printed people's 'shadows' on the ground" (2012:14). It is the subject of survivor poet Toge Sankichi's poem "The Shadow," which for Treat seemed to epitomize the struggle between the documentary and creative impulse discussed above. For him the awful burning power of the bomb led to "a figure for the imprint of the bombing" as "something real, but something only marginally present, a sign with a referent lost except in the memories of those who were there on the sixth of August" (1995:187).

A further example of this can be seen in the work Antbropométries (1960) by the French painter Yves Klein. Part of the museum's permanent collection, it was featured in MOCA's 
2015 Teach Us to Outgrow Our Madness anniversary show, which was part two of their Hiroshima Trilogy: 70th anniversary of the Atomic Bombing exhibitions. Klein used women's bodies to leave blue corpse-like impressions on canvas and the MOCA exhibition makes a connection between these impressions and the A-bomb's silhouettes. Similarly, Kazuo Katase, another artist displayed in the MOCA show, uses reverse photographs of shadows, again implicitly referencing the shadows of the explosion. The bomb, therefore, created its own repertoire of visual images of the marginally present that have been reworked in the documentation, explanation, and artistic response to the awful power it executed.

The second recurring image to note here is damaged and stained clothing. One of the features of Black Rain is the narrator's concern for the state of his own clothing, that of the many injured he meets and of the dead whom he spends time helping to cremate. Clothes are caked in blood, ripped, and blown away - but also occasionally their strangeness is commented upon, for example, in the account of the dead young woman who is found in a stolen kimono covering her naked body. This concern for the clothing of the atomic dead and survivors is most poignantly captured in the photographs of Ishiuchi Miyako whose work was displayed at the PAM show called The 70th Anniversary of the Atomic Bombings on Hiroshima and Nagasaki: War and Peace and also in the special exhibition at MOCA Life $=$ Work, part one of the exhibition trilogy. Miyako's full-sized images on bright white backgrounds have an unnerving and translucent quality that draws attention to both the beauty and simplicity of the clothes, and to their fragility. They also directly reference the damaged clothing that is a significant feature of the displays in the main Hiroshima Peace Memorial Museum. The museum uses items of clothing donated by family members to indicate the physical impact of

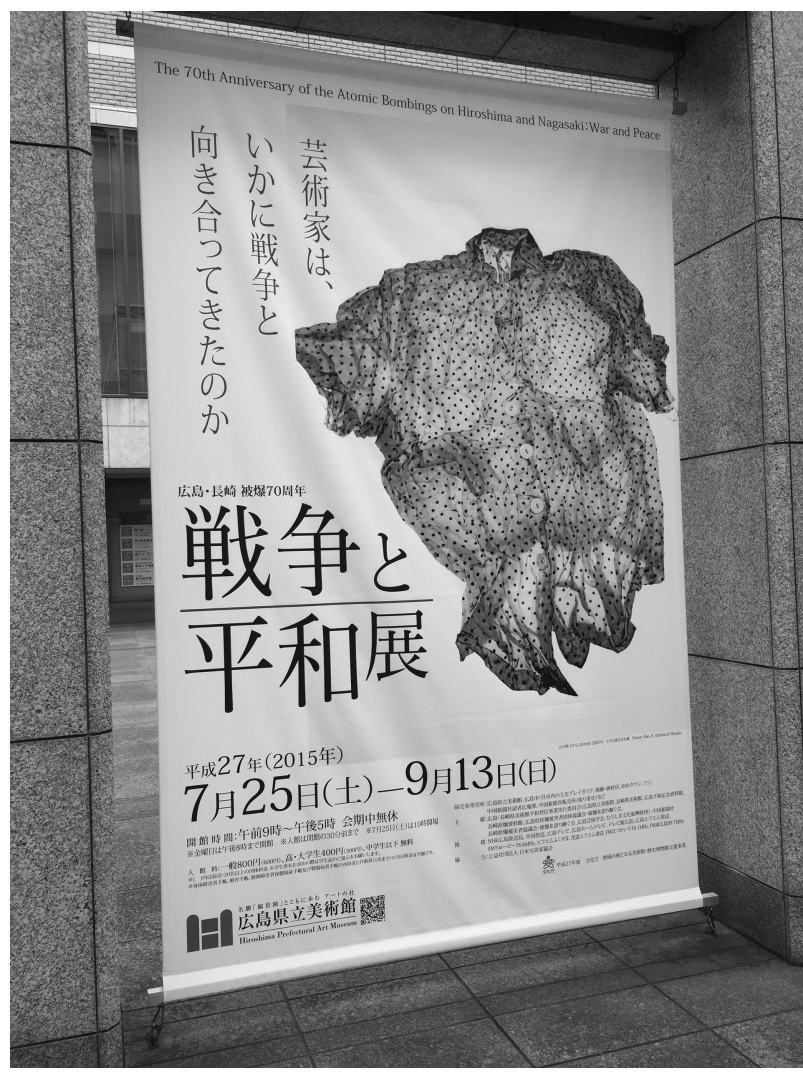

Figure 2. Ishiuchi Miyako's blouse image promoting the exhibition at the Prefectural Art Museum, The 70th Anniversary of the Atomic Bombings on Hiroshima and Nagasaki: War and Peace, 2015. (Photo by James Thompson) the bomb on mostly young bodies: school uniforms, delicate blouses and headwear, many tattered and stained with faded ochre blood. One photograph by Ishiuchi Miyako of a spotty blouse, stained and crumpled, is the poster image of the PAM exhibition and was seen around the city during the days leading up to the commemoration.

Both the torn, stained clothes and the mineralized shadow images evoke people but, of course, mark their absence. Strangely, however, these two recurring images are also of the bodies because the stains and dust are actual traces of those dead and therefore indicate their endur- 


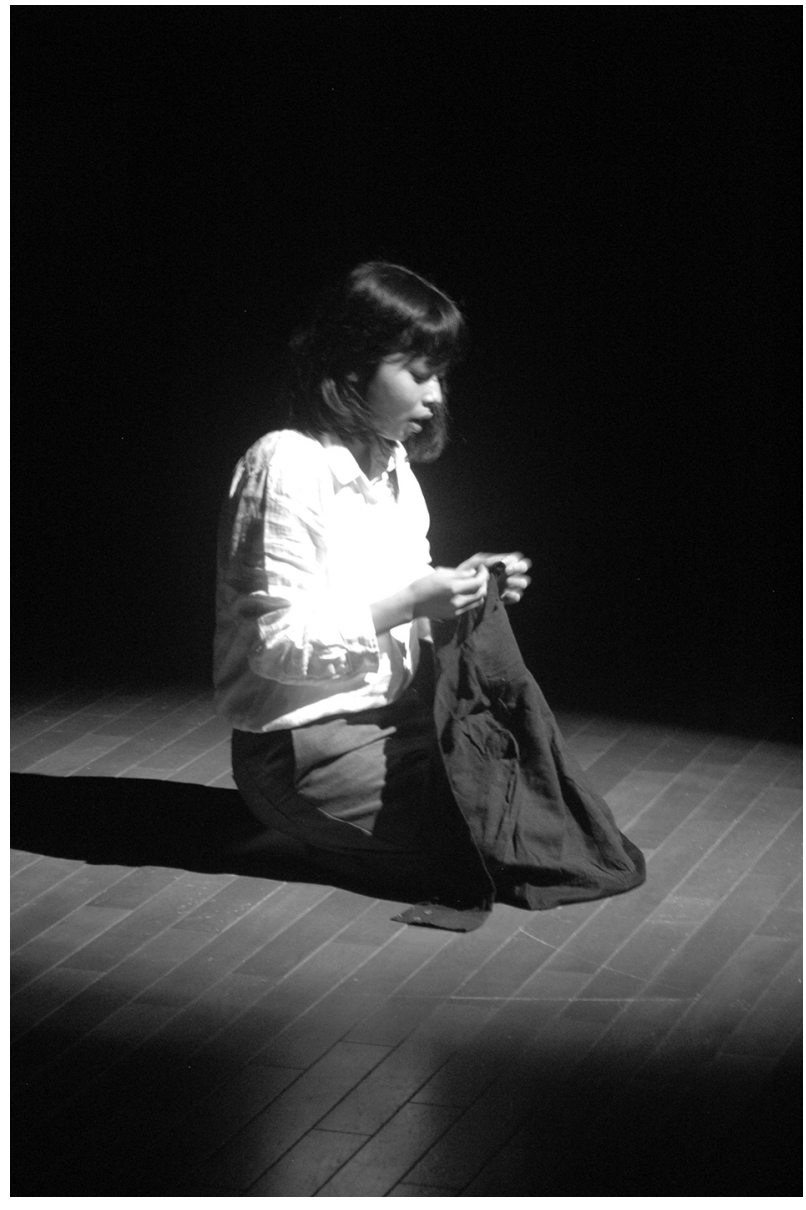

Figure 3. Yoshiko Kajimoto, played by Rio Maniwa, sews the blouse, in Grandchildren of Hiroshima. August 2015, Aster Plaza, International Youth House, Hiroshima. (Photo by London Bubble Theatre) ing, elemental presence. There is a sense, therefore, that these visual tropes of the atomic bombing reference the damage done to people and how they were utterly destroyed, but also present relics that preserve their remains. As already suggested, the bomb asked for no witnesses - it either left you targeted but alive (burnt, damaged, and maybe slowly dying of radiation sickness), or you were incinerated and left "marginally present" as a sign of the bombs awesome power.

Both the imprinting power of the bomb and its subsequent image remnants, and the focus on clothing of survivors and the deceased became central images of the Grandchildren of Hiroshima performance. For example, in a short scene towards the end of the play, the character/survivor Yoshiko Kajimoto sews and folds a blue blouse lit in a tight white spot. She takes great care of the garment and lays it gently in front of her-suggesting a relic of a missing family member. She explains, as she does this, how she wanted to be a schoolteacher, but with the death of her father and her mother from radiation sickness she now needs

to care for her younger brothers. The blouse is gradually transformed as it becomes incorporated into a map made up of clothing placed carefully around the space marking the shapes of the rivers that intersect within the borders of Hiroshima. It shifts from being an archival item from her particular story of loss to a component part of a broader image. I found it difficult to view these articles of clothing without connecting them to the actual mementoes of the dead described above. However, there was also a sense of the play between the particular and the general as clothes that register as markers of individuals transformed into the map of the city, which nominally contains all victims.

In another scene based on the story of 78-year-old Hiroe Sata, she and her mother are searching for her missing brother when she burns her chest on the lid of an air raid shelter. The voice over of the elder is heard over the action:

For that moment, the only thing in her head was my brother. My mother walked around the streets like that. But my burn really hurt. It festered for two days. And, when I was crying and had become unable to move, my mother took off the main towel for the first time. (Setoyama 2015:18) 
Hiroe as a young girl trundles behind her mother complaining about the pain from her injury. The mother cleans the wound with a scarf draped over the girl's delicate shirt. The focus on her burnt and ripped shirt evokes again the damaged clothes that contain the residue of the absent dead and injured.

Grandchildren of Hiroshima also directly references the ash-like shadows mentioned above. In one of the most striking images of the performance, a young girl is laid gently on the floor in a curled, fetal position, and then slowly four other cast members sprinkle dust and plaster over her body. A little later she moves away leaving a glimpse of her body shape on the floor - a shape that remains throughout the rest of the play, trodden and worked into the surface of the stage as the actors move across it in the scenes that follow. Her image - a shadow that suggests the Katase photographs in MOCA, and the impression famously left on the stone of the Sumitomo Bank building, becomes the silhouette over which the rest of the scenes are played out. The play is literally staged over the top of this iconic dust print - almost suggesting that this is the heritage on which this work is based. The key here - and this is where the play also departs from the expected - is that the image is worn away by the performance as it is slowly trodden on throughout the play. The kicking and scattering of the dust, for me, hinted that the play was situated within a tradition, but also started to wear it away; part of a representational legacy attached to the shoes of the actors, but also pushed aside in the act of being walked over.

The clothes and the body outline were important examples of the visual repertoire of Grandchildren of Hiroshima and only two from the sequence of powerful, evocative moments that punctuated the whole piece. The play and the process behind its creation offered a different way of presenting and working with the devastating images and impact of the atomic bomb. Of course, the very fact that this was theatre, not visual art or exhibition display, meant that rather than the evocation of missing bodies, here we had an affective, embodied presentation: the voices of the hibakusha and the moving bodies of the actors were central. The shirt of Hiroe Sata was not portrayed in a sharply lit photograph, but worn and made alive by a young actor. While the incorporation of these iconic images was an important part of the play, I want to emphasize the different approach of Grandchildren of Hiroshima by focusing on another aspect of the performance. The play respected the terrible effect of the bombs, but in the hands of this mixed-generation cast, the youngest being 9 and the oldest above 60, it added something new to the repertoire of bombing imagery. Three moments in particular illustrate, borrowing from Hashimoto, that the play's process and production can be considered an "intergenerational project of biographical repair" (2015:49) — which brings me back to the missing bystander.

First, as I mentioned above, the play is drawn from a series of interviews that the young people in the cast did with hibakusha in 2014 , and these were subsequently worked into a play by 


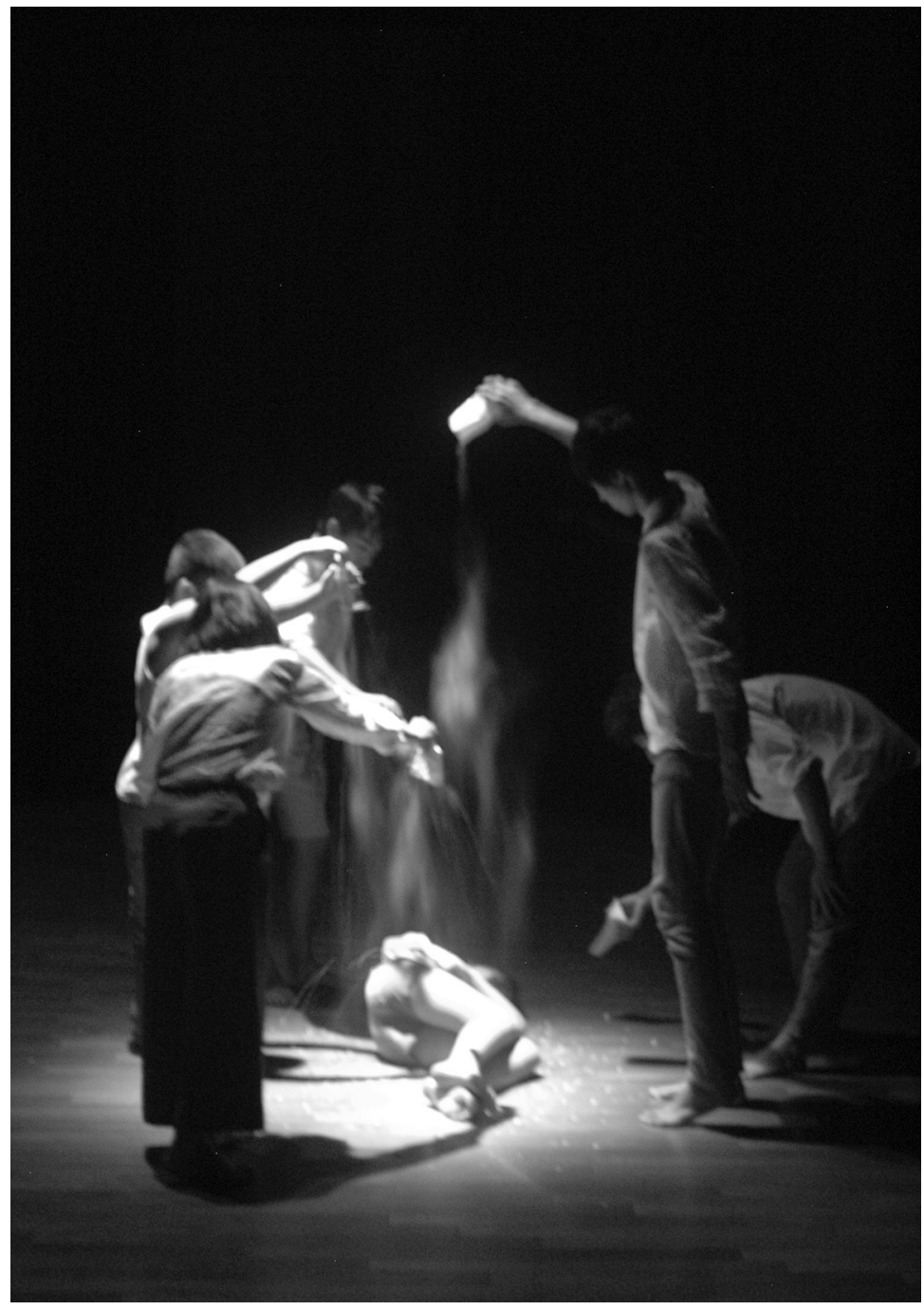

Figure 5. Young actors make the shadow of the bomb by sprinkling dust and plaster over the child curled up on the floor. Grandchildren of Hiroshima, August 2015, in Aster Plaza, International Youth House, Hiroshima. (Photo by London Bubble Theatre) playwright Misaki Setoyama after a series of devising workshops with the cast in spring 2015. However, rather than the play simply presenting the stories of the hibakusha, it instead presents both the stories and the collecting of those stories in the form of the children's interviews with the hibakusha. At a number of key points in the play one child or another is positioned at the end of the stage, voice recorder in hand, speaking her or his interview questions. On the screens behind are photographs of the actual interview and on one occasion, the child featured onstage is the same as in the picture (a number of the children who did the original interviews were also actors, but unfortunately none of the hibakusha interviewees were able to perform for reasons of health or availability). The audience, therefore, sees the young person in dialogue with the elder as the play stages the interview process, not just the outcome of that process.

The thematic content of the play was, therefore, young people learning and then representing the stories of elders, and not simply the content of the stories themselves. As the young interviewer Hibiki says, "I felt I could ask personal questions - ones that I really wanted to find out the answers to" (Setoyama 2015:27). The play, therefore, offered an account of Hibiki and other young people's needs today as much as the stories from the hibakusha: an intervention, I would argue, directly meeting the concerns for the demise of the elderly survivors and the requirement to reimagine how memories of that day might be relayed in a time when the hibakusha are no longer with us.

The second example takes place soon after the play depicts the bomb being dropped with a flash of bright house lights. Three groups of four actors move onto the stage in tight, slowly moving groups, with one or two of them helping to cradle a featureless white puppet - a kind of rag doll, a thin and long-legged humanesque form the size of a small child (fig. 1). Masuji Ibuse gives a devastating account in his novel of a young woman carrying her dead boy on her back on a long train journey to her home village. Here again there was an evocation of the huge number of accounts of the deaths of children in the bombing. Each group carries their 
charge with extraordinary care and focus, but then when they position themselves in groups around the stage, one actor crouches and they become the platform onto which the puppet is brought to life. Each actor gently realizes one part of the puppet's body (somewhat like bunraku), such that the image of loss is transformed into an image of delicate and pointed care. Somehow life is returned to this image of a dead child, through the delicate support and play of the four actors.

The final moment I want to highlight was a very simple series of embraces. In three rapid sequences soon after the bomb has exploded, a child careers across the stage into the arms of a fast approaching adult. While my knowledge that one of the adults was the actual mother of the running girl in this section might have affected my response, there was an overwhelming sensation of relief when the girl found a missing family member, theatrically real-

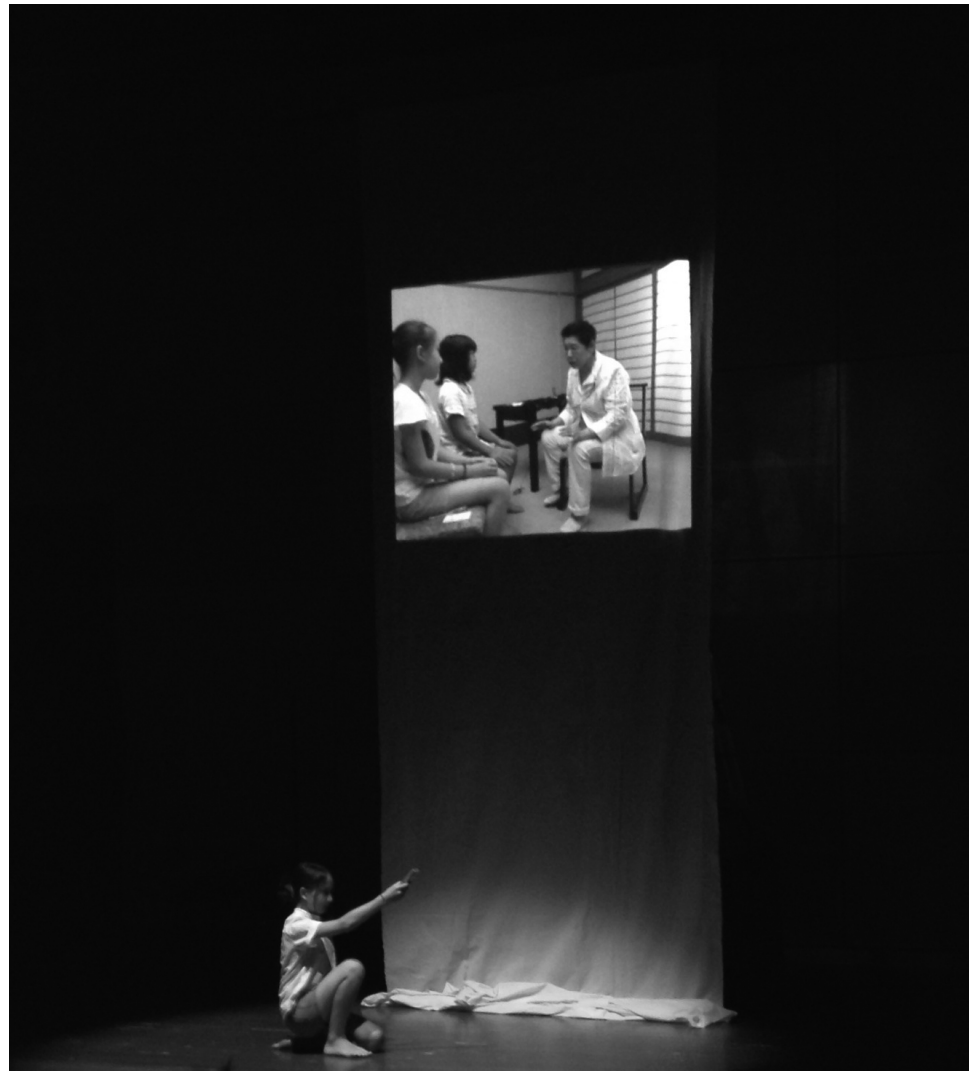

Figure 6. Actor Leona Tashiro playing herself interviewing the hibakusha Hireo Sato. Grandchildren of Hiroshima, August 2015, Aster Plaza, International Youth House, Hiroshima. (Photo by London Bubble Theatre) ized by running followed by an urgent embrace. Seeing a physical closeness between actors of very different ages, coupled as it was with stories of horrendous loss, made these images of bodies actually holding on to each other compelling.

What linked all these scenes was how they presented the importance of the relations between the actors and the relations between characters at different stages of the bombing and its aftermath. The horrendous loss experienced in countless broken relationships, the fragility of human relations as the surviving victims of the bombing gradually rebuilt their lives, and the necessity today of creating relationships between young people and hibakusha were, thus, overriding and recurring themes. The bomb destroyed community and family relationships, which only slowly recovered in the weeks after the attack. As Treat notes "the basic human ties between people were eliminated along with the economic fabric of the communities they inhabited" (1995:8) and these ties were here a central physicalized element of the performance.

As mentioned above, one of the outcomes of the ageing of the hibakusha is their increasingly urgent desire to communicate their experiences to younger people, and this was presented as the framework around which the play was built. The audience sees young people in relation to the elderly as they tell their stories. While powerful for its engagement with the visual language of A-bomb commemoration, the play adds considerably to its effectiveness by also staging the changing dynamics of relationships in pre- and post-bomb Hiroshima and making this the centerpiece of its process, presentational approach, and content. Staged during the 70th anniversary 
when many people were acutely aware that this was perhaps the last major commemoration with a living generation of hibakusha present, this representation of young people retelling the history of the survivors while in dialogue with them placed the performance very much in the present tense, responding to the urgency of the contemporary anniversary.

One way of understanding this "theatre of relations" is to place it within the cosmology of the dominant religious practices within the city region of Hiroshima. Interhuman relations are a given, constituent part of social life according to the Pure Land Buddhist sect, who practice the dominant mode of religious observance in this region. In Miyamoto's study of commemorative and religious practices after Hiroshima, she explains that in this tradition (as with other Buddhist traditions) "the 'self' does not precede its relation to others"; rather one has a set of relations established in advance of your individual existence (2012:62). She continues,

For example, before one is born, one is already part of a web of human relations constituted by mother, father, siblings, uncles, aunts, grandparents, and so on. Rather than being "thrown" into a world independent of human relations, in Buddhism, humans emerge within a web of relationships. (62)

An intergenerational theatre project in this context is one that seeks to strengthen and expand this web of relations - while acknowledging a common history of their intense and devastating rupture. This sense of relations that you are already part of - whether they are with the living or the dead-situates the Grandchildren of Hiroshima project as one in dialogue with the dead and living, to echo Miyamotos's words, and more broadly as a project of postmemory, to use Marianne Hirsch's term (2012). Hashimoto draws this connection by explaining postmemory as "the broader canvas on which biographical narratives of the war experience are repaired as an intergenerational project" (2015:27). Here in this small anniversary initiative we see a micro example whereby biographical narratives are retold between generations in an effort not only to create new relations, but also to repair those that should already be constitutive of human social life. If the broader postwar Japanese project has been reparative then the elders in conversation with youth across the different stages of this intergenerational theatre project can be understood as engaged in a small-scale repair project. And the incorporation of the shadow images and torn garments suggest that the project was also restoring relations with the marginally present dead.

To develop this line of argument a touch further, it is important to go backwards from the play's performances and elaborate more on the process. Just as the staging of strong, then fragile, and then reemerging relationships was a key component of the play, this progression was central to how London Bubble and their collaborators created this work. The devising workshops and rehearsals also functioned as a gradual process of creating relationships among a disparate group of performers, and, therefore, was itself part of the exercise in biographical repair. We often get caught making a simple distinction between process and product when analyzing community-based performance work, but in pointing out that Grandcbildren of Hiroshima has an explicit focus on the notion of relationships, this distinction rightly becomes less clear, and less important. Relationships between older and younger cast members were staged under the lights but were also crafted and realized in the rehearsal process. In observing some of the workshops in April 2015, I was struck by the sense of purpose, respect across generations, and the strong bonds that, to borrow from Miyamoto, emerged from within a "web of relationships." The way that the bomb destroyed relations was, therefore, painfully displayed throughout the piece, but the content of the play and the approach to the process emphasized the human capacity to be mutually reliant and to rebuild. The devising workshops were often joyous, playful, caring, and relaxed. Children worked collaboratively and played with older people during the workshops - and during the performance onstage. The very creation of a piece, therefore, demonstrated one of the important desires of the hibakusha - that around the 70th anniversary of the bombing, their legacy, and their stories, might have a new audience and, crucially, a new genera- 
tion of tellers. Postmemory here is not solely about the generation after in a process of repair, but in the collaborative, creative engagement between generations. The play - in preparation and execution - staged the suggestion that honoring the memory and political aspirations of the hibakusha required dialogue and presentational strategies that were nurturing for both young and old.

\section{The Perpetrator- cum-Victim}

One of the core debates within Japanese postwar memory politics is the extent to which Japan acknowledges its role as perpetrator of crimes during the war or considers itself solely as a victim (Kim 2008). While for Hashimoto this duality can create what she sees as a bifurcated "perpetrator-cum-victim consciousness" (2015:79), it is also framed as the relationship between two other perspectives on the attacks: that they were "an idiosyncratic experience particular to the nation"; and on the other hand, that there exists "a 'universal' memory of the nuclear attack to be preserved and shared by all" (Miyamoto 2012:7). There has been a critique of the latter, because it seems that designating the atomic bomb an attack against all humanity obfuscates the vic-

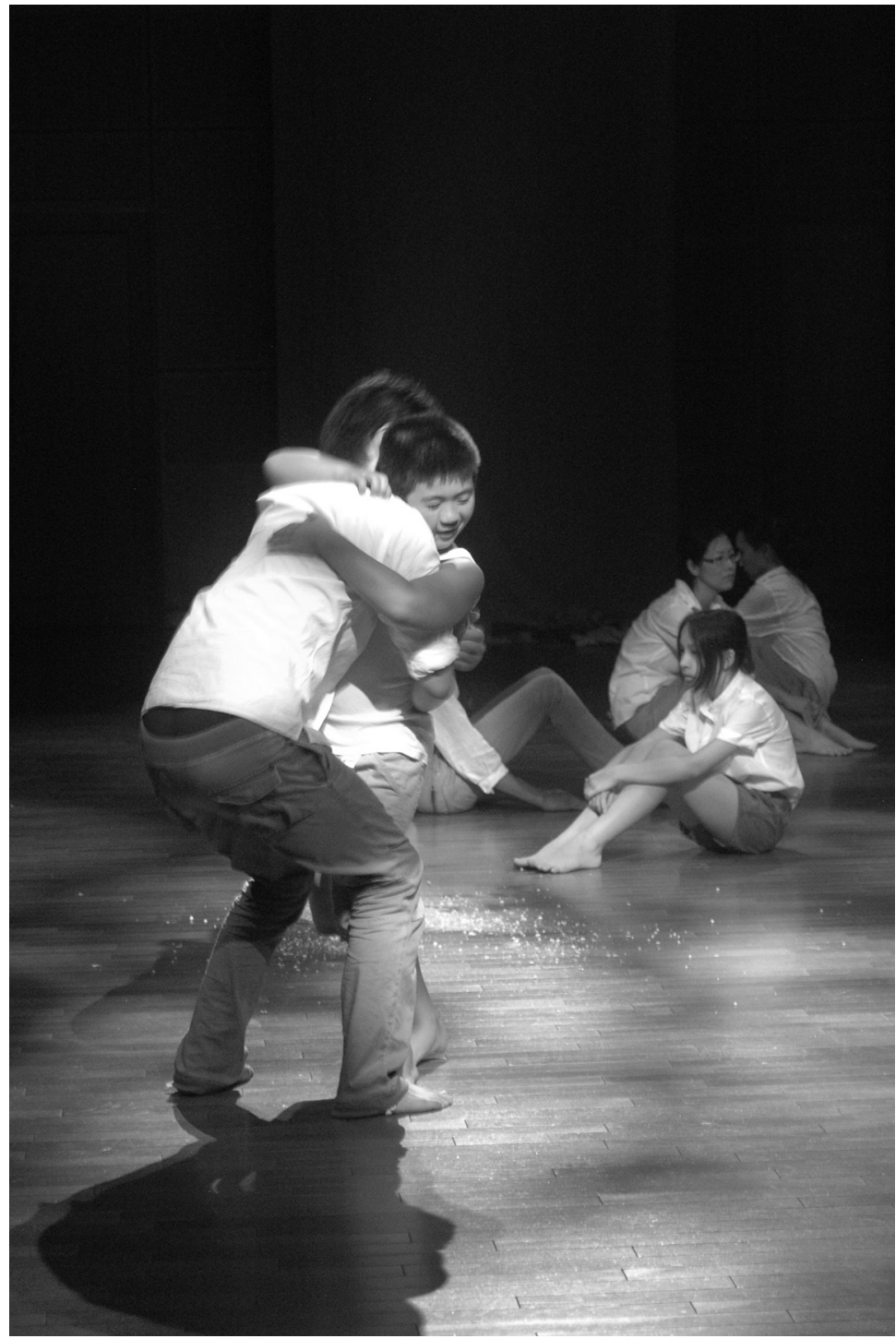

Figure 7. Actor Hiroki Hayashi embraces young actor Hibiki Fujita. In a series of embraces, young actors ran into the arms of an awaiting adult. Grandchildren of Hiroshima, August 2015, Aster Plaza, International Youth House, Hiroshima. (Photo by London Bubble Theatre) timizing role of the Japanese,

and paradoxically ignores the very particular role of the Americans (they dropped the bomb, the bomb was not dropped in the passive tense). Yoneyama, for example, argues that "remembering the atomic destruction of Hiroshima and Nagasaki as events in the history of humanity has significantly contributed to the forgetting of the history of colonialism and racism in the region" (1999:12). However, I believe this distinction is too dichotomous and in many ways understanding the attack against Hiroshima as an attack on all who were there (Japanese citizens, Korean workers/prisoners, American POWs) and, therefore, potentially as a crime against humankind rather than a certain group, does not exclude experiencing the narratives of the bombing as particular to a community or group of individuals. This is explicitly acknowledged by Yoneyama when she seems to counter her own position by arguing: 
[A]t the same time, as I listened closely to the survivors' testimonies and observed the various mnemonic practices that they and others are engaged in, I gradually began to wonder if [...] remembering the ghastly experience of atomic obliteration might have other effects besides uniformly generating a shared imaginary of collective victimization and identity. (1999:214)

What Yoneyama notes here is that when the narrative is experienced in performance - when narratives are "listened to closely" - they "do not in and of themselves produce national selfintoxication on the myth of innocence and victimization, nor do they necessarily endorse the narrative of the national collectivity" (215). The meaning is negotiated by the person listening, watching, and observing; and because it is relational - negotiated in relation to the performer - the experience "might have other effects." It can oscillate between a sense of the universal, collective memory of humanity suffering, and the particular experience of a named hibakusha that is difficult to generalize. If as I have argued there is no bystander in nuclear critique - we are all perpetrators-cum-victims - when the narratives of survivors are brought in front of an audience, the experiences and connections to the bombing of all those present contribute to a differentiated understanding of those memories and how they relate to a diversified experience of the present day. Even though writers such as Miyamoto identify a hibakusha ethic — one that "takes shape

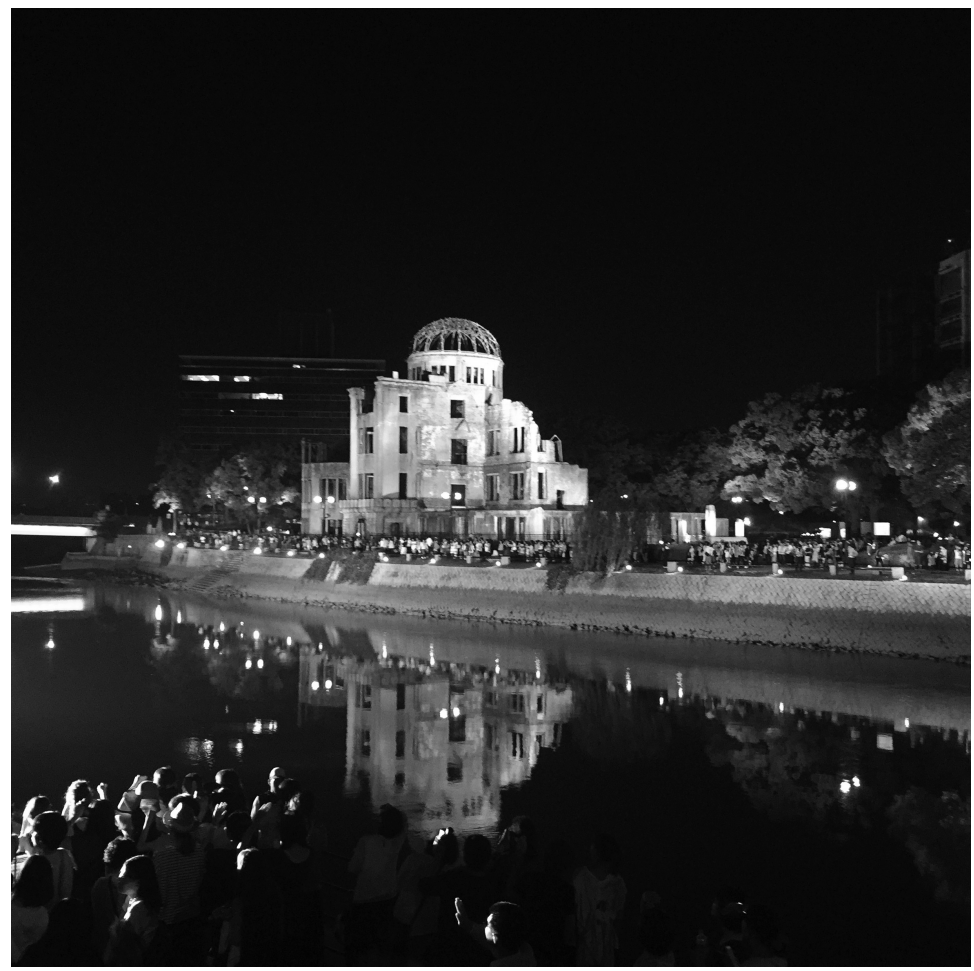

Figure 8. Obon lanterns in front of the Atomic Bomb Dome in Hiroshima, 6 August 2015. (Photo by James Thompson) through the discourse of the hibakusha" and "is resolutely oriented towards the wellbeing of others, regardless of their nationalities and other attributes" (2012:9) — my argument is that it can only take shape as it is listened to or observed by a broader community who have their own particular memory repertoires - their own postmemory. The ethic is realized not as an absolute but is made material across the course of a whole performance project. I would argue that the aim of Grandchildren of Hiroshima was for its process as well as the content of the performance to be orientated toward everyone, regardless of nationality, but I would also suggest that it could not control how a particular audience member might seize hold of a memory as it resonated in their particular life. The argument is that, in Yoneyama's words "countering and deferring the relentless processes through

which nationalizing and renationalizing takes place" requires "strategies of critical remembering" and these are best realized through a relational, embodied performance process where commemorative practices are developed among all participants - that is, young actors, older actors, and audience members - during the whole lifecycle of a project. 
In watching the rehearsals and the first-run performances around the 70th commemoration, it was clear how this project was a critical part of the wider program of events marking the anniversary. Each ceremony - from the formal events with politicians, survivors, and dignitaries in front of a huge public audience in the morning, to an obon lantern floating festival in the evening, and then the broader exhibitions in museums and galleries - were attempts to find a register for responding to an immense horror. What is less acknowledged in discussing these different artistic responses and commemorative performances, is that the atomic bomb was a kind of terror art and the bombing itself can be understood as performance. The bombing, like much aerial bombing done during WWII and since 1945, was a "show" of strength performed for an audience beyond the mushroom cloud. As Treat has written, "in a sense Hiroshima and Nagasaki were a grotesque performance - a 'dramatic finale' [...] - put on for the benefit of audiences in Tokyo and Moscow" (1995:15). Images of the bombing were "for the world" (7) and many European and American adults have grown up with the mushroom cloud as a warning for the future rather than as evidence of terror inflicted at a particular time and on a particular people. Under that cloud, the bombs themselves can also be understood as an imagecreating technology — shadows on walls and ashen shapes were the display it bequeathed. Many visual artists seeking a response are forced to confront these visions and seek to engage with the terror art in ways that repeat, re-present, or negotiate in terms that are already given to them. While I do not want to be overly critical of the exhibitions in Hiroshima, I found some of the artists to be, perhaps understandably, in awe of the art-bomb that their work reflected. In the way that the word "after" designates artists' work that is inspired by or created in the style of a previous artist, much artistic work appeared to be after the A-bomb.

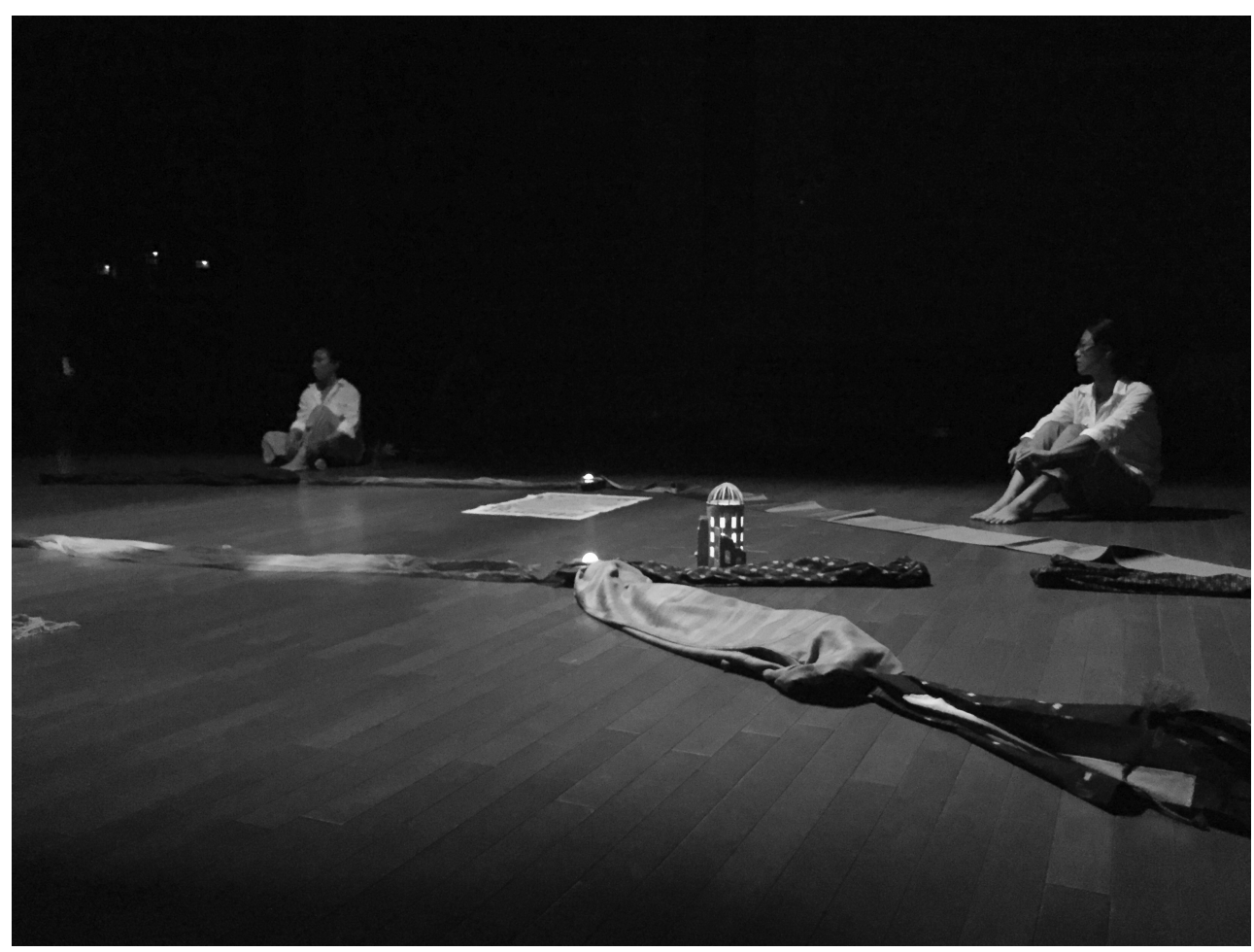

Figure 9. A small model of the Hiroshima Peace Memorial, or Atomic Bomb dome, is lit up in the final scene. Grandchildren of Hiroshima, August 2015, in Aster Plaza, International Youth House, Hiroshima. (Photo by James Thompson) 
My argument is that this did not happen in Grandchildren of Hiroshima to the same degree. Of course, as mentioned above, the play did work with the visual tropes of artistic responses to the bombing found in broader literary and artistic movements. However, in presenting individuals in physical relationship with each other, in building and demonstrating relations between generations in the process, and in the themes of play, there was a bodily interaction that challenged the purely destructive power of the bombs - and the straightforward show of the bombs' power. The children interviewing elders, the adults grasping their thought-to-be-lost kids, and the delicate manipulations of the puppets - all demonstrated human-to-human contact that the atomic bomb destroyed and failed to represent in its shadow images. London Bubble and its Japanese collaborators managed to offer a process that seemed to meet a very contemporary challenge. How, in a time when most surviving hibakusha were children in 1945, do you hold onto a history and set of memories that still have relevance for present-day Japanese and international politics?

The intergenerational theatre model seemed to offer a way of working that in itself suggested a response to this question. Young people meeting and speaking to elders, working and creating with people of different ages, and then staging those processes in a performance that grappled with how people form, lose, and require relationships to survive and thrive. There was an ethics of caring, respecting, and creating that shone through this play that was a mov-

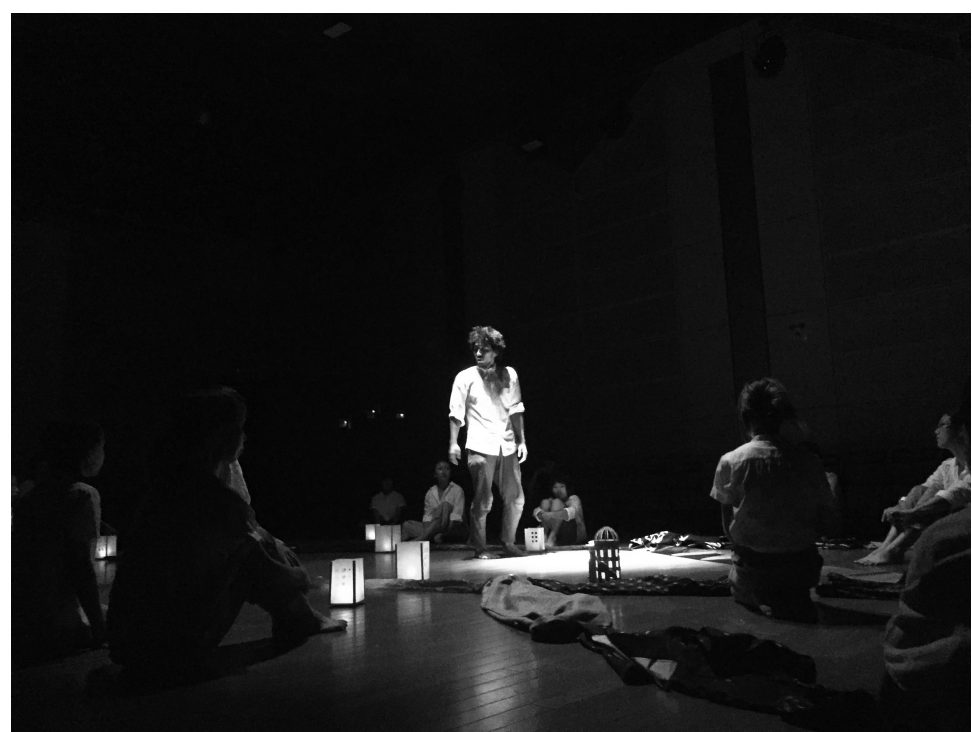

Figure 10. Actor Nori Ikdea stands to deliver final speech among the lanterns and kimono rivers in the final scene. Grandchildren of Hiroshima, August 2015, in Aster Plaza, International Youth House, Hiroshima. (Photo by James Thompson) ing response to the horrendous history of the second world war and to the attacks on the cities of Hiroshima and Nagasaki that were at the apex of its cruelty and craven brutality.

Grandchildren of Hiroshima did not create new shadows of those horrors, but glimmers of new relationships, with and between living and dead, fragments that were offered to an audience invited to make their own meanings: a project of biographical repair that sought to communicate the difficulty of remaining respectful of those narratives yet fully aware of the challenging relevance of the events of 6 August 1945 to the relationships we are part of today.

\section{Epilogue}

In the Hell Fire Pass memorial to Allied prisoners of war, 50 kilometers north of the town of Kanchanaburi in Thailand, a panel in the museum titled "Liberty and Life" displays a quote from a prisoner:

What was surprising and of great relief was the sudden, unexpected Japanese surrender. This was not just a relief from purgatory but also a narrow escape from certain death. Japanese High Command had issued orders that all Allied captives were to be killed in the event of Allied landings in the areas where POWs were held. 
Similarly at the end of his book The Death Railway about the experience of allied prisoners building the railway from Thailand to Burma between 1942 and 1945, Rod Beattie repeats this claim, but this time linking it to the digging of graves:

In Thailand preparations were been [sic] made for the disposal of the POWs. They had been made to dig large trenches around their camps supposedly for protection from the locals. In reality these trenches were burial pits. (2015:148)

I choose not to repeat military or moral arguments for or against dropping the bombs in 1945, made effectively elsewhere (see, for example, Ham [2011] and Hogan [1996]). Suffice to say, I concur with the broad approach of Paul Ham and in particular his statement in his book Hiroshima Nagasaki where he asserts:

Taken together, or alone, the reasons offered in defence of the bomb do not justify the massacre of innocent civilians. We debase ourselves, and the history of civilisation, if we accept that Japanese atrocities warranted an American atrocity in reply. (2011:487)

As stated throughout this article, I am seeking to avoid a model of nuclear criticism where we are designated bystanders awed by the power of the bomb and petitioned to make an intervention on behalf of others. We might be an audience to the performance of the bombs dropped by the United States, but we are also implicated in a different way. While there are many victims, there are also beneficiaries: historically, as suggested by the accounts of the prisoners from Hell Fire Pass; and as contemporary citizens apparently protected by the deterrent capabilities of our new warheads.

The quotes attributed above to Japanese prisoners of war echo one of the few stories my father told me as a child, and retold me as an adolescent who proudly wore the badge of the British Campaign for Nuclear Disarmament. How could I oppose nuclear weapons if, as my father sincerely believed, the dropping of them had saved his life? I now believe that the history of the end of the war is far more complicated than the narrative that presents Japanese surrender as hastened by the bomb, but my youthful self was reproached by a father who had dug his own grave in a prison camp in Thailand. Growing up in a house with no Japanese products, a father's silent fury at their postwar economic success, and experiencing a boy's wide-eyed wonder at seeing tropical ulcer scars on his father's legs and hearing occasional stories of the brutality perpetrated by the Japanese army, meant that any encounter with the people of Hiroshima was always framed, for me personally, as biographical repair.

It is, therefore, obvious that in watching Grandchildren of Hiroshima I was not a bystander, but someone positioned, by one questionable version of history, as a person whose life was made possible by the bombing of the city. However, the argument here has been that this is not exceptional: we are all, in Europe, the United States, and Asia, children and grandchildren of Hiroshima. We are beneficiaries of the bombs, or at least, of the stories told ever since to justify the bombing of the two cities, and of the logic of the aerial bombing of cities and the deliberate mass killing of civilians as a legitimate act of war. The bombs performed and continue to perform for us all. In Hiroshima, in the summer of 2015, the significance of this position was felt through the brief relationships I built with a company of Japanese youth and elders — seeing them play, speak, care, laugh, and passionately debate the meaning of nuclear war in their diverse lives. However, it took a moment in a lift as my dad's Japanese words were heard through the counting of a young girl, for the implication of a narrative that justified the massacre of a city's population - and its children — to be felt by me for all its shattering, gutwrenching reality. Of course, perhaps this was not a reality —in Benjamin's words, "the way it really was" - but my experience with this performance project, from that moment on, made me seek to seize hold of that embodied flash, and painstakingly engage with the process not as bystander but as a participant, fully involved in a tiny program of careful, captivating repair. 


\section{References}

Beattie, Rod. 2015. The Death Railway: A Brief History of the Thailand-Burma Railway. Fourth edition. Kanchanaburi: Thailand Burma Railway Centre.

Benjamin, Walter. 1968. Illuminations: Essays and Reflections. New York: Harcourt Brace Jovanovich.

Carlson, Marvin. 2003. The Haunted Stage: The Theatre as Memory Machine. Ann Arbor: The University of Michigan Press.

Dower, John W. 2012. Ways of Forgetting, Ways of Remembering: Fapan in the Modern World. New York: The New Press.

Geras, Norman. 1998. The Contract of Mutual Indifference: Political Philosophy After the Holocaust. London: Verso.

Ham, Paul. 2011. Hiroshima Nagasaki: The Real Story of the Atomic Bombings and their Aftermath. New York: St Martin's Press.

Hashimoto, Akiko. 2015. The Long Defeat: Cultural Trauma, Memory, and Identity in fapan. Oxford: Oxford University Press.

Hirsch, Marianne. 2012. The Generation of Postmemory: Writing and Visual Culture After the Holocaust. New York: Columbia University Press.

Hogan, Michael J., ed. 1996. Hiroshima in History and Memory. Cambridge: Cambridge University Press.

Ibuse, Masuji. 2012. Black Rain. Translated by John Bester. New York: Kodansha USA.

Jacobs, Robert, ed. 2010. Filling the Hole in the Nuclear Future: Art and Popular Culture Respond to the Bomb. New York: Lexington Books.

Kim, Mikyoung. 2008. "Pacifism or Peace Movement?: Hiroshima Memory Debates and Political Compromises." Fournal of International and Area Studies 15, 1:61-78.

Martin, Carol. 2012. Theatre of the Real. Basingstoke: Palgrave Macmillan.

Miyamoto, Yuki. 2012. Beyond the Mushroom Cloud: Commemoration, Religion, and Responsibility after Hiroshima. New York: Fordham University Press.

Saito, Hiro. 2006. "Reiterated Commemoration: Hiroshima as National Trauma." Sociological Theory 24, 4:353-76.

Setoyama, Misaki. 2015. Grandchildren of Hiroshima. Unpublished script.

Treat, John Whittier. 1995. Writing Ground Zero: Fapanese Literature and the Atomic Bomb. Chicago: The University of Chicago Press.

Yoneyama, Lisa. 1999. Hiroshima Traces: Time, Space, and the Dialectics of Memory. Berkeley: University of California Press.

Zwigenberg, Ran. 2014. Hiroshima: The Origins of Global Memory Culture. Cambridge: Cambridge University Press. 